\title{
English Through Culturally Familiar Contexts: A Pilot Study in Japan
}

\author{
Robert Sheridan \\ Kindai University, Nara, Japan \\ Kathryn M. Tanaka \\ Otemae University, Nishinomiya, Japan \\ Nicholas Hogg \\ Osaka Yuhigaoka Gakuen High School, Osaka, Japan
}

\begin{abstract}
As more attention is given to the subject of global Englishes, consideration of the different methods by which English is taught has become more important. Across Asia, increasingly teachers have turned to culturally specific textbook design, yet few scholars have conducted studies that demonstrate the practical effectiveness of such texts in Asian contexts. To bridge this research gap, we conducted a study wherein students in two English reading classes at a Japanese university were given the same readings, with passages reflecting either Japanese or foreign cultural contexts. Through pre- and post-lesson tests, we gauged the effectiveness of culturally familiar proper nouns on vocabulary recall and content comprehension. Overall, we demonstrate that culturally familiar contexts in EFL study might have a positive impact on language learning for students.
\end{abstract}

As English receives attention as a global language, the question of culture in language education becomes more prominent. Much of this attention has been given to the distinction between teaching English as a foreign or global language (EFL) and teaching English as a second language (ESL). Broadly, an ESL course is an English language course taught to a nonnative speaker in a country where English is the dominant language. The goal of ESL instruction is cultural and linguistic assimilation. In contrast, an EFL course is an English language class in a country where the dominant language is not English. The goal of EFL instruction is to teach English as a means for communication with the world, rather than assimilation. As English becomes a global language, there has been a shift toward EFL in English Language Teaching (ELT) (Leung \& Dewey, 2010) and a move toward the incorporation of L1 vocabulary and contexts into the L2 classroom (Cook, 2001; Nation, 1997; Tavakoli, Shirinbakhsh, \& Rezazadeh, 2013; Timor, 2012). However, little attention has been given to the effectiveness of culturally familiar contexts in EFL education in Asia. This paper presents findings from a pilot study on the impact of culturally familiar and unfamiliar contexts on students' vocabulary and content recall across two English proficiency levels in a Japanese university. It discusses the implications of the preliminary results and quantitatively demonstrates the benefits of cultural familiarity in EFL course content.

Language Education in Asia, 2016, 72), 88-99. https://doi.org/10.5746/LEiA/16/V7//2/A03/Sheridan_Tanaka_Hogg 
In our research, we use the term context to refer to the culturally specific knowledge the readers bring to the text, as discussed by scholars of schema theory (Carrell \& Eisterhold, 1983; Stott, 2001). Carrell and Eisterhold (1983) hypothesized that "New information, new concepts, new ideas can have meaning only when they can be related to something the individual already knows" (p. 553). They further posited that "The background knowledge that second language learners bring to the text is often culture-specific" (p. 562). We draw on the schema theory and the previously mentioned studies to argue for the importance of culturally familiar contexts in EFL education.

\section{The Instruction of English and Local Culture}

Many textbook activities require not only knowledge of the English language, but also of Western culture. Yet today, more students learn not with the objective of living abroad but with the goal of English competence for employment within their own country (Crystal, 2003; McKenzie, 2010). For students who may have minimal interest in or knowledge of Western culture, struggles with foreign cultural contexts can present an additional roadblock to language acquisition. Many textbooks for a global market use western names and places; yet even proper nouns can pose challenges to students learning a foreign language (Jalilifar \& Assi, 2008; Ketchum, 2006).

For this reason, scholars are giving increasing attention to the retention of local cultural identity in language education (Mizumura, 2015; Pennycook, 1994, 2001; Tanaka, 2015). Drawing on work by scholars who argue for the place of L1 in the L2 classroom (Cook, 2001; Littlewood \& $\mathrm{Yu}, 2011$; Nation, 1997; Timor, 2012), studies have used the cultural schema theory to argue for the place of cultural adaptation in EFL courses, in particular in Middle Eastern contexts (Jalilifar \& Assi, 2008; Keshavarz, Atai, \& Ahmadi, 2007; Tavakoli et al., 2013). In Asian countries, there is a shift towards culturally familiar textbook design, as can be seen in Cambodia (Gentner, 2015). It is clear that as English becomes a common global language, a reconsideration of the way in which English is taught is necessary.

\section{Culturally Familiar Contexts in the EFL Classroom}

There has been some research into the pedagogical effectiveness of culturally familiar contexts in ELT. Drawing on Steffensen, Joag-Dev, and Anderson (1979), a number of educators and researchers have argued that the retention of $\mathrm{L} 1$ cultural contexts is an important scaffolding strategy in L2 education. Alptekin (2006) referred to this pedagogical tactic as nativization, which he defined as the "sociological, semantic and pragmatic adaptation of the textual and contextual cues of the original story into the learner's own culture, while keeping its linguistic and rhetorical content essentially intact" (p. 497).

Further studies around the Middle East, Turkey, and Spain indicate the relevance of learnercentered pedagogy rooted in culturally familiar texts and contexts (Demir, 2012; Erten \& Razı, 2009; Jalilifar \& Assi, 2008; Kuhi, Asl, \& Yavari, 2013; Pulido, 2004). Demir (2012) conducted a study wherein groups of 7 th grade students in Turkey were given nativized and what he refers to as "denativized" or "authentic" texts with the "name of the cities, countries, events, and dates" reflecting either Turkish or foreign contexts (p. 191). His study demonstrated that students who read the culturally familiar version of the text scored higher in reading comprehension and vocabulary recall. Culturally familiar contexts in texts have been shown to increase comprehension (Alptekin, 2006; Erten \& Razı, 2009; Tavakoli et al., 2013) and vocabulary retention (Pulido, 2004). 
While nativization has been gaining ground in Middle Eastern pedagogical practices in particular, it has received comparatively less attention in East Asia. At the same time, studies into culturally familiar texts and EFL education in Japan echo the results above: Chihara, Sakurai, and Oller (1989) and Sasaki (2000) demonstrated that students who read culturally familiar texts had measurably better vocabulary scores and improved reading comprehension. The results of these studies support the hypothesis that nativized texts and original texts yield clear benefits to language learners.

However, the above studies do have some weaknesses. Demir (2012) went beyond altering proper nouns by changing historical and cultural contexts together with the national holiday (Independence Day in the United States or Turkey) in his reading selection, making a direct comparison of student responses to the piece more difficult. Furthermore, these studies have tended to focus on single classes with a uniform level of proficiency.

Our pilot study investigates the impacts of familiar and unfamiliar cultural contexts in vocabulary recall and content comprehension in Japan, beginning from the hypothesis that familiar cultural contexts promote both vocabulary recall and comprehension. The study was conducted across proficiency levels, a dimension that the studies above have not considered.

\section{Methodology}

\section{Participants}

Our study had 41 participants (28 females, 13 males) enrolled at a small, private university in western Japan. They were aged 18 to 24 . All students were enrolled in yearlong intermediate or advanced level English courses that used current events and newspaper stories in their classes. Two of the authors taught the two classes in this study.

Prior to our study, we administered the New General Service List Test (NGSLT; Stoeckel \& Bennett, 2015) to our participants to gauge their initial vocabulary level. The NGSLT was used because it effectively covers the first several thousand words of English that make up ninety percent of the core of everyday language used in reading, listening, and speaking (Browne, Culligan, \& Phillips, 2013). Each of the five approximately 560-word bands of the New General Service List contributes 20 items to the NGSLT, making a total of 100 items. The NGSLT results, mean TOEIC scores, and details of the two classes in this study are given in Table 1.

\section{Table 1}

\section{Class Data}

\begin{tabular}{ll}
\hline Class 1 & Class 2 \\
\hline 22 participants (16 females, six males) & 19 participants (12 females, seven males) \\
1st year students & 2nd, 3rd, and 4th year students \\
TOEIC: 300 or above & TOEIC: 400 or above \\
NGSLT class average: $65.7 \%$ & NGSLT class average: $78.7 \%$ \\
\hline
\end{tabular}

\section{Research Design}

The design of the study was comparative with two groups. After the NGSLT, the instructors gave two sets of paired reading assignments out of thirteen readings per semester. The assignments were from newspaper stories that instructors either chose from familiar cultural contexts or altered to either reflect culturally familiar or unfamiliar contexts. Of the four articles, two were from a Japanese newspaper: "Man made living by selling stolen golf balls" ("Man made living," 2007) and "Checking attendance by mobile phone" (Mizutani \& Mizutani, 2007, 
p. 133); one from a British newspaper: "Out of love for his cats" ("Cat burglar," 2013); and one from a Singaporean newspaper: "Man charged \$3,000 for punching queue-jumper in the eye in MRT train" (Chong, 2015). We chose newspapers as a source of authentic language usage (see also Demir, 2012; Tanaka, 2015).

For the first and second articles, one class received the original culturally familiar context version while the other class received an article that was identical apart from proper nouns or monetary denominations altered to reflect foreign cultural contexts. For the third and fourth articles, both classes received the same foreign or familiar context version to set a control group for the study. Table 2 gives details on how the readings were assigned to each class.

\section{Table 2}

\section{The Class Readings}

\begin{tabular}{lll}
\hline Article & Class 1 & Class 2 \\
& Cultural Context & Cultural Context \\
\hline Man made living by selling stolen golf balls & Foreign (Arabic) & Japanese \\
\hline Checking attendance by mobile phone & Japanese & Foreign (Arabic) \\
\hline Out of love for his cats & Foreign (Kenyan) & Foreign (Kenyan) \\
\hline $\begin{array}{l}\text { Man charged } \$ 3,000 \text { for punching queue-jumper in } \\
\text { the eye in MRT train }\end{array}$ & Japanese & \multirow{2}{*}{ Japanese } \\
\hline
\end{tabular}

The third article, with a culturally familiar context, was changed to have a foreign context and the opposite was done for the fourth article to test a perceived bias in student discussion and homework answers. Arabic and Kenyan contexts were specifically chosen as the foreign contexts to avoid western culture, which many students have some familiarity with through popular culture. Each article was assigned as a homework reading. Prior to reading the article, each class was given an identical pretest at the end of class. Students were then given either the culturally familiar or unfamiliar article and identical homework assignments. After study and class discussion in the next meeting, both groups were given the same posttest. Although four articles were used in class, due to space limitations, this paper introduces the tests, articles, and homework through examples from one article in particular.

\section{Example Article Used as a Research Instrument}

"Man Made Living by Selling Stolen Golf Balls" appeared in Japan News (2007) and included names and currency given in Japanese cultural contexts. The original article was given to students in Class 2. The article was altered to take place in an Arabic cultural context for Class 1. Table 3 shows excerpts of the article; the text was not bolded or italicized in the articles given to students. We added two paragraphs to promote classroom discussion by introducing moral ambiguity and to slightly increase the length of the articles. 
Table 3

The Difference of Contexts in Article 1

Article 1 Given to Class 1 (Foreign context)

Man made living by selling stolen golf balls

$A B U$ DHABI- A man believed to have made his living over the past 15 years by selling golf balls that he took from ponds on golf courses late at night has been charged with theft, according to police.

Mohammad Moftizadeh of Abu Dhabi, United Arab Emirates, was arrested on April 27 and later charged with stealing 1,376 balls, worth about 41,000 dirhams, from a pond at Sadiyat Beach Gold Club in Abu Dhabi, United Arab Emirates, the police said. . . .

"Such theft is a crime against society," said Nassar Sarjah, one of the arresting police officers. "In $\boldsymbol{A b u}$ Dhabi, golf is an exclusive sport. To carelessly come onto a course and disturb the ponds in search of balls harms the course. ..."

Moftizadeh, on the other hand, stated that after he lost his hand in a factory accident, he had no other skills. . . ". . . I was careful not to hurt the course," he said in his defense. ". . . It was the only way I could live."
Article 1 Given to Class 2

(Japanese context)

Man made living by selling stolen golf balls

GIFU- A man believed to have made his living over the past 15 years by selling golf balls that he took from ponds on golf courses late at night has been charged with theft, according to police.

Tadayoshi Kusanagi of Toyota, Aichi Prefecture, was arrested on April 27 and later charged with stealing 1,376 balls, worth about $¥ 41,000$, from a pond at Gifu Kokusai Country Club in Yamagata, Gifu Prefecture, the police said. ...

"Such theft is a crime against society," said Hideo Imanashi, one of the arresting police officers. "In Japan, golf is an exclusive sport. To carelessly come onto a course and disturb the ponds in search of balls harms the course...."

Kusanagi, on the other hand, stated that after he lost his hand in a factory accident, he had no other skills . . . ". . I I was careful not to hurt the course," he said in his defense. ". . . It was the only way I could live."

VocabProfile (Cobb, 2015), a computer program, identified the words the articles contained from each of the frequency bands as shown in Table 4. We replaced items in the articles beyond the fourth set of 1000 high frequency (K4) English words with simplified lexical items.

Table 4

\section{Breakdown of the Lexical Items in Article 1}

\begin{tabular}{lll}
\hline Frequency level bands & $\begin{array}{l}\text { Current profile } \\
\text { (token \%) }\end{array}$ & Examples of items on pretest \& posttest \\
\hline K1 & $77.13 \%$ & None \\
K2 & $8.92 \%$ & according to, search, hurt \\
K3 & $3.88 \%$ & arrest, retail, pond \\
K4 & $1.16 \%$ & theft, abandon \\
OFF & $8.91 \%$ & None (Japanese or foreign proper nouns) \\
\hline
\end{tabular}

Note. K1 is the first 1000, K2 the second 1000, K3 the third 1000, and K4 the fourth 1000 most frequent English words.

To test vocabulary recall and content comprehension, we used pretests and posttests with both classes. By comparing the lexical text analysis to the student results on the NGSLT, we were able to select words that the students were less likely to know. Items were chosen from the second to fourth sets of 1000 high frequency words of English (K2-K4; see Table 4). Items from the first 1000 high frequency words were ignored because the majority of the students from both classes had achieved a near perfect score on this section of the NGSLT. Each pretest and posttest contained 15 multiple choice vocabulary questions with three distractors each and three content questions (see Table 5). The questions on the tests were identical for both classes. The lexical items for the 15 multiple choice questions were selected using VocabProfile. 


\section{Table 5}

Examples of Test Questions for Article 1

\begin{tabular}{|c|c|}
\hline Examples of multiple choice vocabulary questions & Examples of content questions \\
\hline $\begin{array}{l}\text { according to: According to the newspaper, it is } \\
\text { going to rain tomorrow. } \\
\text { allowed by }\end{array}$ & $\begin{array}{l}\text { 1. Do you believe it is always wrong to steal? Why or } \\
\text { why not? }\end{array}$ \\
\hline $\begin{array}{l}\text { reported by } \\
\text { made by }\end{array}$ & $\begin{array}{l}\text { 2. Which is more important: the needs of the } \\
\text { individual or the needs of society? }\end{array}$ \\
\hline $\begin{array}{l}\text { arrest: The man was arrested. } \\
\text { kept after school } \\
\text { questioned by the police } \\
\text { taken and kept by the police } \\
\text { questioned by parents }\end{array}$ & $\begin{array}{l}\text { 3. Do you believe luxury sports such as golf are } \\
\text { important to society? Why or why not? }\end{array}$ \\
\hline
\end{tabular}

\section{Results, Discussion, and Limitations}

\section{Vocabulary Recall Through Culturally Familiar and Unfamiliar Contexts}

As shown in Table 6, both classes achieved gains in their mean vocabulary scores from pretests to posttests for all four articles. However, due to participant attrition in the fall semester and the fact that the crossover design was not followed in the fall semester, only the vocabulary gains for articles read in the spring semester were analyzed.

Repeated-measure $t$ tests were conducted to evaluate whether the students had made significant gains from vocabulary pretests to posttests. Table 7 shows that while both classes made vocabulary gains that would be significant with $p$ values of less than .05 , when the Bonferroni adjustment was applied to the critical $P$ value $(P$ value of $0.5 /$ number of tests $=0.5 / 4=$ $0.0125)$, only 3 of the 4 test results were found to be statistically significant. Furthermore, the mean vocabulary gains of students who read articles with Japanese contexts did not exceed those who read the same articles set in foreign contexts. Thus no further analysis was necessary to determine that the results did not support the hypothesis that greater vocabulary gains would be made by students reading culturally familiar contexts versus students reading assignments with culturally unfamiliar contexts. 
Table 6

Mean Score Comparisons Between Pretests and Posttests

\begin{tabular}{|c|c|c|c|c|c|c|c|}
\hline Semester & Article & Class & Context & Tests & $N$ & Mean & Gains \\
\hline \multirow[t]{8}{*}{ Spring } & Golf & 1 & Foreign & Pretest & 22 & 10.18 & Post-Pre \\
\hline & & & & Posttest & 22 & 11.91 & +1.727 \\
\hline & & 2 & Japanese & Pretest & 19 & 11.89 & Post-Pre \\
\hline & & & & Posttest & 19 & 13.42 & +1.526 \\
\hline & Attendance & 1 & Japanese & Pretest & 23 & 11.57 & Post-Pre \\
\hline & & & & Posttest & 23 & 12.35 & +.783 \\
\hline & & 2 & Foreign & Pretest & 19 & 11.63 & Post-Pre \\
\hline & & & & Posttest & 19 & 12.53 & +.895 \\
\hline \multirow[t]{8}{*}{ Fall } & Cats & 1 & Foreign & Pretest & 13 & 9.62 & Post-Pre \\
\hline & & & & Posttest & 13 & 10.62 & +1.000 \\
\hline & & 2 & Foreign & Pretest & 12 & 10.08 & Post-Pre \\
\hline & & & & Posttest & 12 & 11.33 & +1.250 \\
\hline & Queue & 1 & Japanese & Pretest & 14 & 10.93 & Post-Pre \\
\hline & & & & Posttest & 14 & 12.50 & +1.571 \\
\hline & & 2 & Japanese & Pretest & 10 & 12.20 & Post-Pre \\
\hline & & & & Posttest & 10 & 13.60 & +1.400 \\
\hline
\end{tabular}

Table 7

Mean Score Comparisons Between Pretests and Posttests of Articles 1 \& 2

\begin{tabular}{lllllllll}
\hline Article & Class & Tests & $N$ & Min & Max & Mean & Gains & $P$ \\
\hline Golf & 1 & Pretest & 22 & 6 & 15 & 10.18 & Post-Pre & Pre / Post Pair \\
& & Posttest & 22 & 6 & 15 & 11.91 & 1.727 & $.000^{*}$ \\
\cline { 2 - 8 } & 2 & Pretest & 19 & 7 & 15 & 11.89 & Post-Pre & Pre / Post Pair \\
& & Posttest & 19 & 10 & 15 & 13.42 & 1.526 & $.011^{*}$ \\
\hline Attendance & 1 & Pretest & 23 & 8 & 15 & 11.57 & Post-Pre & Pre / Post Pair \\
& & Posttest & 23 & 8 & 15 & 12.35 & .783 & .044 \\
\cline { 2 - 8 } & \multirow{2}{*}{2} & Pretest & 19 & 7 & 14 & 11.63 & Post-Pre & Pre / Post Pair \\
& & Posttest & 19 & 10 & 15 & 12.53 & .895 & $.004^{*}$ \\
\hline
\end{tabular}

Note. *mean gains are significant at $p<.0125$

There were a few limitations which may have contributed to the lack of support of the findings in the quantitative vocabulary component of this pilot study. First, due to participant attrition and the fact that the crossover design was not followed in the fall semester, the fall semester data was excluded from this portion of the analysis. Thus, there was less opportunity to find supporting evidence. Second, only 15 items were included on the vocabulary test, which given the results, was in all likelihood too few to properly explore the differences between the two classes. This was especially evident in the lack of difficult items, which led to test-ceiling effects. For example, in Class 1, only one student out of the 22 achieved a perfect score on the Golf vocabulary pretest, whereas in Class 2, four students out of 19 did so, thus limiting potential gains for Class 2. This alone may have prevented Class 2 from achieving more substantial vocabulary gains. Third, given that the hypothesis was that a Japanese cultural context would make the text easier to comprehend and more meaningful than the same text with a foreign cultural context, thus better supporting vocabulary recall, comprehension should also have been tested quantitatively. In the content questions, we did not ask specific details 
about each article, but instead designed questions to be open-ended and opinion-based to facilitate more language use. This made quantitative assessment of comprehension too difficult. For this reason, the above data is focused on vocabulary. The vocabulary test results did not provide support for our hypothesis, yet due to our limitations, further research into the use of culturally familiar contexts and their effect on vocabulary recall is warranted.

\section{Analysis of Homework Answers and Posttest Content Results}

In addition to the vocabulary tests, students' homework and posttest content questions were examined to explore the difference in responses to culturally familiar and unfamiliar texts. This qualitative analysis clearly indicated students had different responses. Most importantly, their answers indicated that the way that students read differed depending on the cultural context of the article. Each class was assigned the same three questions as homework for the reading assignment (see Table 8 ). The results yield some interesting information about the ways in which culture impacts how students read and approach material.

\section{Table 8}

\section{Homework Questions}

Homework Questions

1. Write three main points or events from the article.

2. Write three open-ended discussion questions you have after reading the article.

3. Write your opinion about the article.

Regarding the homework for the first article on golf balls, the students in Class 1 who read the foreign text expressed a great diversity of opinion, and their posttest answers reinforce this. Some students argued that stealing was wrong under any circumstances, while others thought the loss of a hand and the fact that no one was using the golf balls made the theft forgivable. Finally, two students wrote in their homework that the assignment was too difficult and they did not understand enough of the article to articulate an opinion.

At the same time, the homework responses indicate the foreign setting of the article implicitly influenced the way students read and approached the denativized article. For example, Student 1 wrote, "There is a tremendous gap between the rich and the poor in the United Arab Emirates. I want to lose the gap." Student 2 stated that "In Japan, people who has handicap work hard. They are make effort always." Student 3 said, "I think, that is why there is poor country. It is the story that Japanese can't think it. Because there is a way elsewhere to make my living in Japan. So I understood that this is a national difference."

Such answers illustrate that students approach content differently when it is not culturally familiar. Students implicitly or explicitly contrasted the material they believed to be foreign with how they imagined a similar story would take place in Japan, demonstrating that texts can be read in ways that are either culturally based or culturally biased (Carrell \& Eisterhold, 1983).

Similarly, students in Class 2 also expressed diverse opinions, but the majority of students in Class 2 wrote that stealing the golf balls was wrong, yet the circumstances of the case made it understandable. Several students in Class 2 remarked, as did Student 3, that "the story was sad," or as Student 4 said, "this is a very sensitive story." Furthermore, several students made comments such as that of Student 5: "Japanese government should make more institutions that can help people like him. And he should have research about work and institutions too before stealing." Indeed, overall, a two-thirds majority of students in Class 2 said that while they were sorry for the man who was arrested, there must be other alternatives and theft was wrong. No 
student expressed such an opinion in Class 1.

The differences in answers indicate that cultural contexts influenced the ways students read the assignment. Students in Class 1 read comparatively, contrasting what they thought happened in a foreign context with what they believed could possibly happen in Japan. Students in Class 2 responded more emotionally to the native version of the story. This suggests that students are more emotionally invested in articles about their home countries, but further research is needed.

In addition, students in Class 2 who read the golf ball article with Japanese context ranked it very highly among their thirteen total course readings at the end of semester. Student 6 liked the article because "I can understand both position the police and the suspect." Student 7 wrote "I like it because it is a problem between both parties if it is a real crime or not."

In contrast, Class 1 students who read the golf ball article set in Abu Dhabi did not rank it highly and expressed frustration with the level of difficulty. While part of this may be because of the difference in student English proficiency levels, the homework and in-class discussions made it apparent that some of the frustration with the article was a direct result of the foreign setting.

\section{Directions for Future Research}

The most obvious limitations to this study concerned participant attrition and the failure to follow a crossover design throughout the course of the study. In the future, research will be conducted on compulsory classes to maintain a consistent $N$ size throughout the academic year. Another limitation concerned the method for assessing comprehension. Student understanding was only assessed at the lexical level and it seemed that there were too few questions on the tests and that they were not difficult enough. Future tests will also include more difficult lexical items to cast a larger net and avoid the ceiling effect, and comprehension questions, which will include the proper nouns and will be used to test for both factual and higher order thinking using a 1 or 0 scoring system. In addition, students will be informed of the original contexts of their reading assignments after completing the unit and asked if that information changes the way they think about the article. Finally, to better quantitatively gauge student interest, students will be asked to indicate their reactions to the article on a 7-point Likert scale on the posttest.

\section{Conclusions}

While our study is ongoing, our initial results suggest culturally familiar contexts in EFL instruction might have a positive impact on language learning for students. The homework answers and class discussions in particular suggest that students were more engaged with articles that had a familiar cultural base.

An important contribution of the study is our evidence that in the absence of culturally-based, familiar contexts, students may approach assignments with cultural biases, changing their way of reading and responding to the work. This affective difference in the students' ways of reading created by culturally familiar contexts or lack thereof has not been demonstrated in any previous work.

It should be noted that the present study is preliminary, with a focus on vocabulary and content in a Japanese setting. Despite its focus on a single cultural context, our initial research suggests some intriguing conclusions and avenues for further research. 


\section{Author Note}

Robert Sheridan, Faculty of Agriculture, Kindai University, Nara, Japan; Kathryn Tanaka, Institute of International Education and Department of Cultural and Historical Studies, Otemae University, Nishinomiya, Japan; Nicholas Hogg, Osaka Yuhigaoka Gakuen High School, Osaka, Japan

Robert Sheridan (M.S.Ed.) is a full-time lecturer in the Faculty of Agriculture at Kindai University in Nara, Japan. His research interests include vocabulary acquisition, CLIL, extensive reading, motivation, and assessment.

Kathryn M. Tanaka (Ph.D.) is a tenured lecturer in the Institute of International Education and Department of Cultural and Historical Studies of Otemae University in Nishinomiya, Japan. Her research interests include CLIL, bilingual education, and culture and literature. Recent publications include "Teaching literature in translation in the EFL classroom" in the JALT2014 Conference Proceedings.

Nicholas Hogg (M.S.Ed.) is a full-time instructor and international-exchange liaison at Osaka Yuhigaoka Gakuen High School in Osaka, Japan. His professional interests include second language fluency development, vocabulary acquisition, educational research design, and assessment.

Correspondence concerning this article should be addressed to Robert Sheridan, Faculty of Agriculture, Kindai University. E-mail: robert@nara.kindai.ac.jp or robert.kindai@gmail.com 


\section{References}

Alptekin, C. (2006). Cultural familiarity in inferential and literal comprehension in L2 reading. System, 34(4), 494-508. https://doi.org/10.1016/j.system.2006.05.003

Browne, C., Culligan, B., \& Phillips, J. (2013). The New General Service List. Retrieved from http://www.newgeneralservicelist.org/

Carrell, P. L., \& Eisterhold, J. C. (1983). Schema theory and ESL reading pedagogy. TESOL Quarterly, 174), 553-573. https://doi.org/10.2307/3586613

Cat burglar: Japanese man steals $£ 112,000$ to feed his 120 cats. (2013, December 12). The Telegraph. Retrieved from http://www.telegraph.co.uk/news/worldnews/asia/japan/10513592/Cat-burglarJapanese-man-steals-112000-to-feed-his-120-cats.html

Chihara, T., Sakurai, T., \& Oller, J. W., Jr. (1989). Background and culture as factors in EFL reading comprehension. Language Testing, 6(2), 143-149. https://doi.org/10.1177/026553228900600202

Chong, E. (2015, December 8). Man fined \$3,000 for punching a man in the eye in MRT train. The Straits Times. Retrieved from http://www.straitstimes.com/singapore/courtscrime/man-fined-3000-for-punching-a-man-in-the-eye-in-mrt-train

Cobb, T. (n.d.). Compleat web VP! [computer program]. Accessed 13 May 2015 at http://www.lextutor.ca/vp/comp/

Cook, V. (2001). Using the first language in the classroom. The Canadian Modern Language Review, 5オ(3), 402-423. https://doi.org/10.3138/cmlr.57.3.402

Crystal, D. (2003). English as a global language. London, England: Cambridge University Press. https://doi.org/10.1017/CBO9780511486999

Demir, Y. (2012). The effect of background knowledge and cultural nativization on reading comprehension and vocabulary inference. Journal of Educational and Instructional Studies in the World, 2(4), 188-198. Available at http://www.wjeis.org/FileUpload/ds217232/File/22.demir.pdf

Erten, İ. H., \& Razı, S. (2009). The effects of cultural familiarity on reading comprehension. Reading in a Foreign Language, 21(1), 60-77. Retrieved from http://nflrc.hawaii.edu/rfl/April2009/articles/erten.pdf

Gentner, M. T. (2015). Teaching English to Cambodian learners: A task-based approach for effective classroom instruction. Pathum Thani, Thailand: Bangkok University Press.

Jalilifar, A., \& Assi, R. (2008). The role of cultural nativization in comprehension of short stories in EFL reading contexts. Language, Society and Culture Journal, 26, 62-79. http://www.aaref.com.au/attachment.aspx?id=2075

Keshavarz, M., Atai, M., \& Ahmadi, H. (2007). Content schemata, linguistic simplification, and EFL readers' comprehension and recall. Reading in a Foreign Language, 19(1), 19-33. http://nflrc.hawaii.edu/rfl/April2007/keshavarz/keshavarz.pdf

Ketchum, E. M. (2006). The cultural baggage of second language reading: An approach to understanding. Foreign Language Annals, 39, 22-42. https://doi.org/10.1111/j.19449720.2006.tb02247.x

Kuhi, D., Asl, M., \& Yavari, M. (2013). The relationship between awareness raising activities and students' proficiency in reading comprehension of culturally-bound materials. Mediterranean Journal of Social Sciences, 4(3), 515-522. https://doi.org/10.5901/mjss.2013.v4n3p515

Littlewood, W., \& Yu, B. (2011). First language and target language in the foreign language classroom. Language Teaching, 44(1), 64-77. https://doi.org/10.1017/S0261444809990310 
Leung, C., \& Dewey, M. (2010). English in English Language Teaching: Shifting values and assumptions in changing circumstances. Working Papers in Educational Linguistics, 25(1), 1-15. Available at

http://www.gse.upenn.edu/sites/gse.upenn.edu.wpel/files/archives/v25/Dewey\%26Leun g.pdf

Man made living by selling stolen golf balls. (2007, May 27). Japan News, p. 2.

McKenzie, R. (2010). The social psychology of English as a global language: Attitudes, awareness and identity in the Japanese context. Dordrecht, Heidelberg, London, New York: Springer Science + Business Media. https://doi.org/10.1007/978-90-481-8566-5

Mizumura, M. (2015). The fall of language in the age of English (J. W. Carpenter, Trans.). New York, NY: Columbia University Press.

https://doi.org/10.7312/columbia/9780231163026.001

Mizutani, O., \& Mizutani, N. (2007). Nihongo through newspaper articles (Revised ed.). Tokyo, Japan: The Japan Times.

Nation, P. (1997). L1 and L2 use in the classroom: A systematic approach. TESL Reporter, 30(2), 19-27. Available at https://ojs.lib.byu.edu/spc/index.php/TESL/article/download/3616/3390

Pennycook, A. (1994). The cultural politics of English as an international language. London, England: Longman.

Pennycook, A. (2001). Critical applied linguistics: A critical introduction. Mahwah, NJ: Lawrence Erlbaum.

Pulido, D. (2004). The effect of cultural familiarity on incidental vocabulary acquisition through reading. The Reading Matrix, 4(2), 20-53. Available at http://www.readingmatrix.com/articles/pulido/article.pdf

Sasaki, M. (2000). Effects of cultural schemata on students' test-taking processes for cloze tests: A multiple data source approach. Language Testing, 17(1), 85-114. https://doi.org/10.1177/026553220001700104

Steffensen, M., Joag-Dev, C., \& Anderson, R. (1979). A cross-cultural perspective on reading comprehension. Reading Research Quarterly, 15(1), 10-29. https://doi.org/10.2307/747429

Stoeckel, T., \& Bennett, P. (2015). A test of the New General Service List. Vocabulary Learning and Instruction, 4(1), 1-8. https://doi.org/10.7820/vli.v04.1.stoeckel.bennett

Stott, N. (2001). Helping ESL students become better readers: Schema theory applications and limitations. The Internet TESL Journal, 711). Retrieved from http://iteslj.org/Articles/StottSchema.html

Tanaka, K. M. (2015). Teaching literature in translation in the EFL classroom. In P. Clements, A. Krause, \& H. Brown (Eds.), JALT2014 Conference Proceedings (pp. 386-394). Tokyo, Japan: JALT. Available at http://jalt-publications.org/files/pdfarticle/jalt2014proc_040.pdf

Tavakoli, M., Shirinbakhsh, S., \& Rezazadeh, M. (2013). Effect of cultural adaptation on EFL reading comprehension: The role of narrative nativization and foreign language attitude. World Applied Sciences Journal, 21(11), 1587-1596. Available at https://www.idosi.org/wasj/wasj21(11)13/6.pdf

Timor, T. (2012). Use of the mother tongue in teaching a foreign language. Language Education in Asia, 3(1), 7-17. https://doi.org/10.5746/LEiA/12/V3/I1/A02/Timor 